\title{
Bee Wax Propolis Extract as Eco-Friendly Corrosion Inhibitors for 304SS in Sulfuric Acid
}

\author{
Femiana Gapsari, Rudy Soenoko, Agus Suprapto, and Wahyono Suprapto \\ Mechanical Engineering Department, Faculty of Engineering, Brawijaya University, Jalan MT Haryono 167, Malang 65145, Indonesia \\ Correspondence should be addressed to Femiana Gapsari; femianagapsari@gmail.com and Rudy Soenoko; rudysoen@yahoo.com
}

Received 16 June 2015; Revised 27 August 2015; Accepted 30 August 2015

Academic Editor: Ramazan Solmaz

Copyright (C) 2015 Femiana Gapsari et al. This is an open access article distributed under the Creative Commons Attribution License, which permits unrestricted use, distribution, and reproduction in any medium, provided the original work is properly cited.

\begin{abstract}
The inhibition properties of bee wax propolis (BWP) extract on the 304SS in $0.5 \mathrm{M}$ sulfuric acid were conducted using potentiodynamic polarization, EIS, and XRD. Quercetin (2-(3.4-dihydroxy phenyl)-3.5.7-trihydroxy-4H-chromen-4-one) was identified as the main compound in the BWP extract based on FTIR and HPLC analysis. The results showed that the inhibitor could retard the corrosion rate of $304 \mathrm{SS}$ in $0.5 \mathrm{M}$ sulfuric acid which reached $97.29 \%$ and $91.42 \%$ at $2000 \mathrm{ppm}$ based on potentiodynamic polarization and EIS measurement, respectively. The inhibition efficiency decreased with increasing temperature. The inhibition mechanism of BWP extract on the 304SS was physisorption and obeyed Temkin adsorption isotherm equation. The thin protective layer on the 304SS surface was confirmed by XRD.
\end{abstract}

\section{Introduction}

Stainless Steel (SS) type 304 is widely used as the main construction in the nuclear, petroleum, energy, food, and medicine industry as well as the electrochemical industry [1]. The 304 SS can be applied in various fields of industry and nonindustry compared to other types. It has high corrosion resistance in aggressive environments, especially under high temperature conditions on gas environment. The corrosion resistance is from stable chrome oxide layer on the metal surface that protects the metal from corrosive environment attack [2].

The acid pickling, cleaning, and descaling and also oil acidizing are meant to remove the dirt, scale, and rust on steel. The process uses strong acids, such as hydrochloric acid $(\mathrm{HCl})$ and sulfuric acid $\left(\mathrm{H}_{2} \mathrm{SO}_{4}\right)$ in various concentrations [3]. However, the high reactivity of sulfuric acid can cause the 304SS to be corroded. This is due to the dissolution of the protective layer of chromium oxide containing nickel directly. Therefore, the corrosion was controlled by using inhibitor. This was done because it is a simple application and has no effect on the production process [4]. The use of inhibitors in general has been widely studied to solve a metal corrosion problem in acid solution [5-11]. Inhibitors are substances that can reduce and prevent the metal reaction in its environment with a very small amount [12-16].

Formerly, inhibitors which were widely used were inorganic inhibitors. However, inorganic inhibitors have a lot of disadvantages. The salts form of chromate compounds has high toxicity that is harmful to the environment. Another inorganic inhibitor is titanium (IV) oxide (TiO) that is rarely used because of being very expensive. Moreover, inorganic inhibitors have characteristics that increase the corrosion rate if used in excess amount [17]. Therefore, the use of inorganic inhibitors has been replaced by organic inhibitors which are more eco-friendly, cheaper, and easier to obtain [18-25]. The efficient inhibitors are organic compounds that contain electronegative atom (i.e., $\mathrm{N}, \mathrm{S}$, or $\mathrm{O}$ ) or double bond in their structure [26-28]. Unfortunately, the synthetic organic compounds can be toxic and hazardous for environment, so today many researchers use organic compounds from natural materials as inhibitor. Organic inhibitors from natural material used are part of the plant [29], such as extract of the leaves [5, 18], seeds [19], fruit [20], and rod [21]. Aside from the parts of plants, honey is also a natural material that have been reported to be good for retarding the corrosion rate of copper, carbon steel alloys, and aluminum in salt environment [15, 24, 25]. 
Honey is a natural result that is processed by bees from the nectar of flower or plant parts. However, the price of honey is expensive and it is commonly used as the drug makes it nonefficient as an inhibitor on an industrial scale. Therefore, we use the bee wax propolis (BWP) extract as inhibitor in the present study. The BWP is a waste of honeycomb and contains a compound similar to honey so it is possible to be used as a corrosion inhibitor. The present study is devoted to investigation of the inhibition efficiency of the BWP extract for corrosion of $304 \mathrm{SS}$ in $0.5 \mathrm{M} \mathrm{H}_{2} \mathrm{SO}_{4}$ solution. The corrosion measurement was performed by an electrochemical method. The influence of temperature on the inhibition efficiency and mechanism of inhibition and the formation of a passive layer will also be discussed.

\section{Materials and Methods}

2.1. Sample Preparation, Extraction, and Inhibitor Characteristics. The 304SS in the present study had chemical composition (wt\%): $0.04 \%$ C, $0.52 \%$ Si, $0.92 \% \mathrm{Mn}, 0.030 \%$ P, $0.002 \%$ $\mathrm{S}, 9.58 \% \mathrm{Ni}, 18.15 \% \mathrm{Cr}$, and bal. Fe. The $304 \mathrm{SS}$ specimens with $0.2 \mathrm{~mm} \times 1 \mathrm{~cm} \times 1 \mathrm{~cm}$ dimension were prepared for the working electrode (WE). The WE was added to epoxy resin with a geometric exposed surface area measuring $1 \mathrm{~cm}^{2}$ and connected to the electrolyte. Before the experiment, the specimen surface was polished with emery paper of grades 400 to 1200 consecutively.

The BWP is used as honeycomb waste that had been squeezed 3-4 times. These wastes were usually in the form of wax and remaining of sticky honey. The BWP was extracted by liquid-liquid method in order to obtain the optimum conditions. The extract of BWP was characterized by Fourier Transform Infrared Spectroscopy (FTIR) and High Performance Liquid Chromatography (HPLC). FTIR analysis aims to determine the functional groups contained in the BWP extract. FTIR spectra showed the characteristic wavenumber of flavonoids, which were a carbonyl group $(\mathrm{C}=\mathrm{O}$, ketone $)$ at $1712.67 \mathrm{~cm}^{-1}, \mathrm{OH}$ at $3367.48 \mathrm{~cm}^{-1}$, and aromatic group at $1649.02,1514.02$, and $1460.01 \mathrm{~cm}^{-1}$. Identification of the main compounds in the BWP extract was followed by HPLC analysis. The result of HPLC identification showed that quercetin (2-(3,4-dihydroxyphenyl)-3,5,7trihydroxy-4H-chromen-4-one) was the greatest compound in the BWP extract.

2.2. Electrochemical Measurement. Standard ASTM (American Standard and Testing) G31 was the reference used in this measurement [31]. One batch contained $0.5 \mathrm{M}$ sulfuric acid solution in various concentrations of BWP extract. There were 7 batches with BWP extract composition as follows: 0, 1000, 2000, 3000, 4000, 5000, and $6000 \mathrm{ppm}$. The tests were carried out at room temperature $(298 \mathrm{~K})$. The optimum concentration obtained from the measurement of room temperature was later tested at temperature variations (298, 308, 318, and $328 \mathrm{~K})$. Electrochemical measurement was carried out at room temperature using an Autolab PGSTAT128N. The optimum concentration of inhibitor was tested at temperature variations $(298,308,318$, and $328 \mathrm{~K})$. Specimens that have been prepared were then assembled into an electrochemical cell with $\mathrm{Ag} / \mathrm{AgCl}(3 \mathrm{M} \mathrm{KCl})$ as reference electrode (RE) and platinum as an auxiliary electrode (AE) and then immersed in a batch for 30 minutes. The starting potential was $-1.0 \mathrm{~V}$ and the scan rate range extended up $+1.0 \mathrm{~V}$ at Open Circuit Potential (OCP) with voltage scan rate of $0.001 \mathrm{~V} / \mathrm{s}$. Inhibition efficiency is calculated by $[7,25,32]$

$$
\mathrm{IE} \%=\frac{I_{\text {corr }}-I_{\operatorname{corr}(i)}}{I_{\text {corr }}} \times 100,
$$

where $I_{\text {corr }}$ and $I_{\text {corr }(i)}$ are corrosion current density in medium without and with the addition of inhibitors.

The Electrochemical Impedance Spectroscopy (EIS) measurement was conducted in the range frequency from 1000 to $1 \mathrm{~Hz}$ with amplitude of $15 \mathrm{~mA}$ peak-to-peak AC signal galvanostatically at the OCP. The working electrode was immersed in the test solution for 30 minutes to establish constant signal at open circuit potential. Inhibition efficiency using EIS method was formulated by $[7,33]$

$$
\mathrm{IE} \%=\frac{R_{\mathrm{ct}(i)}-R_{\mathrm{ct}}}{R_{\mathrm{ct}(i)}} \times 100,
$$

where $R_{\mathrm{ct}}$ dan $R_{\mathrm{ct}(i)}$ are the resistance of the charge transfer medium without and with the addition of inhibitors. The impedance parameters were calculated by fitting the experimental result to equivalent circuit using NOVA 1.7 software.

\section{Results and Discussion}

3.1. $p H$ Measurement. There were no significant changes in $\mathrm{pH}$ by the addition of various concentrations of inhibitor. The average $\mathrm{pH}$ value of the solution without inhibitor was 1.5 with 3 replications. The presence of inhibitor $(1000,2000$, and $3000 \mathrm{ppm}$ ) in solution gives the average $\mathrm{pH}$ value of $1.48,1.47$, and 1.44 , respectively.

3.2. Potentiodynamic Polarization Measurements. Data obtained from polarization are used to analyze the adsorption mechanism [10]. The polarization curves obtained were extrapolated to calculate corrosion parameters such as $I_{\text {corr }}, E_{\text {corr }}, \beta_{a}$, and $\beta_{c}[19,24]$. Figures 1(a) and 1(b) show the Tafel plots for 304SS in $0.5 \mathrm{M} \mathrm{H}_{2} \mathrm{SO}_{4}$ without and with various concentrations of inhibitor and the representative of the extrapolation example of Tafel plot for $304 \mathrm{SS}$ in $0.5 \mathrm{M} \mathrm{H}_{2} \mathrm{SO}_{4}$ solution, respectively. The results of extrapolation of Tafel plots are shown in Table 1 .

The optimum IE\% was $97.27 \%$ which was gained on the addition of $2000 \mathrm{ppm}$ (Table 1). These results indicated that the corrosion rate of 304 SS can be inhibited effectively with the increase of concentration that reached $2000 \mathrm{ppm}$. Increasing of IE\% value is proportional to decreasing of current density. Data obtained from polarization are used to analyze the adsorption mechanism [24]. At concentration of $2000 \mathrm{ppm}$, the smallest current density was produced due to the uniform adsorption of inhibitor molecules on metal surfaces. Optimum inhibition efficiency obtained at a concentration of $2000 \mathrm{ppm}$ and decreased with increasing concentration of inhibitor was suspected physical adsorption 
TABLE 1: Inhibition efficiency calculation of polarization measurements.

\begin{tabular}{|c|c|c|c|c|c|}
\hline Concentration of inhibitor (ppm) & $\beta_{a}(\mathrm{~V} / \mathrm{dec})$ & $\beta_{c}(\mathrm{~V} / \mathrm{dec})$ & $E_{\text {corr }}(\mathrm{V})$ & $I_{\text {corr }}\left(\mathrm{A} / \mathrm{cm}^{2}\right)$ & IE $(\%)$ \\
\hline 0 & 0.059 & -7.958 & -0.286 & $2.19 \times 10^{-5}$ & - \\
\hline 1000 & 0.224 & -0.794 & -0.033 & $2.67 \times 10^{-6}$ & 87.79 \\
\hline 2000 & 0.103 & 0.172 & -0.001 & $5.93 \times 10^{-7}$ & 97.29 \\
\hline 3000 & 0.062 & 0.359 & -0.278 & $7.97 \times 10^{-6}$ & 63.60 \\
\hline 4000 & 0.082 & -0.707 & -0.280 & $8.32 \times 10^{-6}$ & 61.99 \\
\hline 5000 & 0.053 & 0.033 & -0.301 & $9.77 \times 10^{-6}$ & 55.38 \\
\hline 6000 & 0.079 & -0.177 & -0.279 & $1.72 \times 10^{-5}$ & 21.64 \\
\hline
\end{tabular}

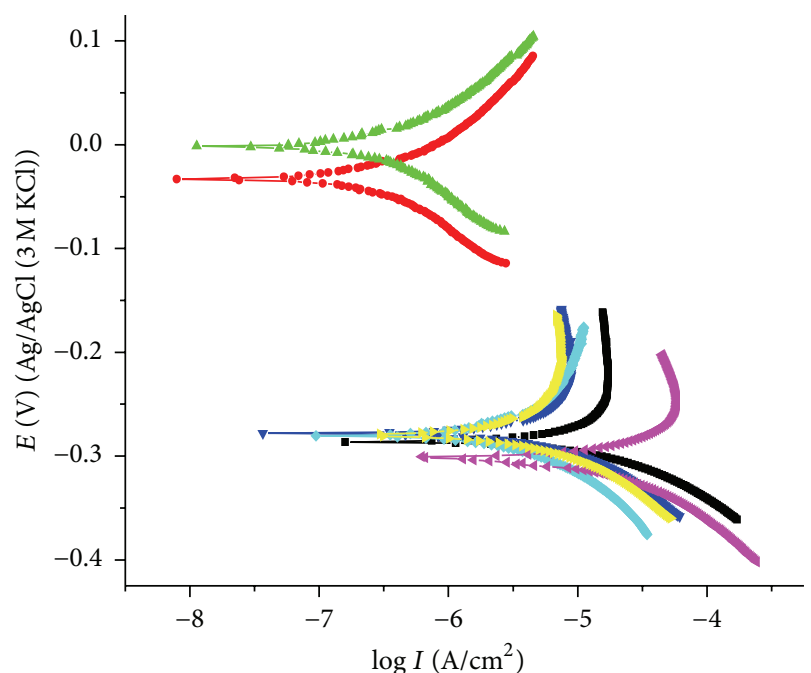

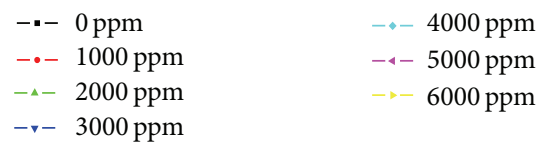

(a)

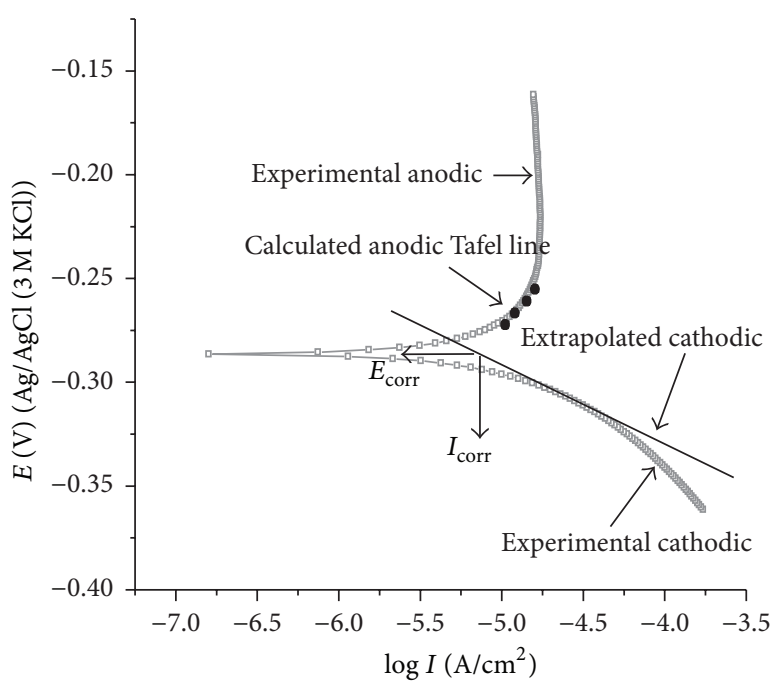

(b)

FIgURE 1: (a) Tafel plots with various concentrations of inhibitor and (b) extrapolarization of Tafel plot for $304 \mathrm{SS}_{\text {in }} 0.5 \mathrm{M} \mathrm{H}_{2} \mathrm{SO}_{4}$ solution.

mechanism [35]. When the inhibitor addition is more than the optimum concentration, the solution will be saturated. There is possibility for strong interaction between inhibitor molecules in the solution and inhibitor which was attached in the surface of metal so that this layer will be released again into solution [36]. According to Table 1, anodic Tafel constants $\left(\beta_{a}\right)$ and cathodic Tafel constants $\left(\beta_{c}\right)$ are shown to be irregular. Irregularity of $\beta_{a}$ and $\beta_{c}$ showed that the BWP extract was a mixed inhibitor that modify the mechanism of anodic dissolution and cathodic hydrogen evolution $[9,37]$.

The assumption of physisorption can be confirmed by the polarization measurement at temperature variations (Figure 2). Certainty is indicated by decreased inhibition efficiency with increasing temperature (Table 2). Physisorption showed the relatively weak dipoles interactions and could cause desorption of BWP extract from the metal surface at high temperature $[1,5]$. Based on $[38,39]$, IE\% decrease with increasing temperature indicated that inhibitor molecules were physically adsorbed on metal surfaces. Increasing of temperature was likely initiated to stop the interaction and the inhibition was not absorbed in the metal surface that caused decreases in inhibition efficiency.

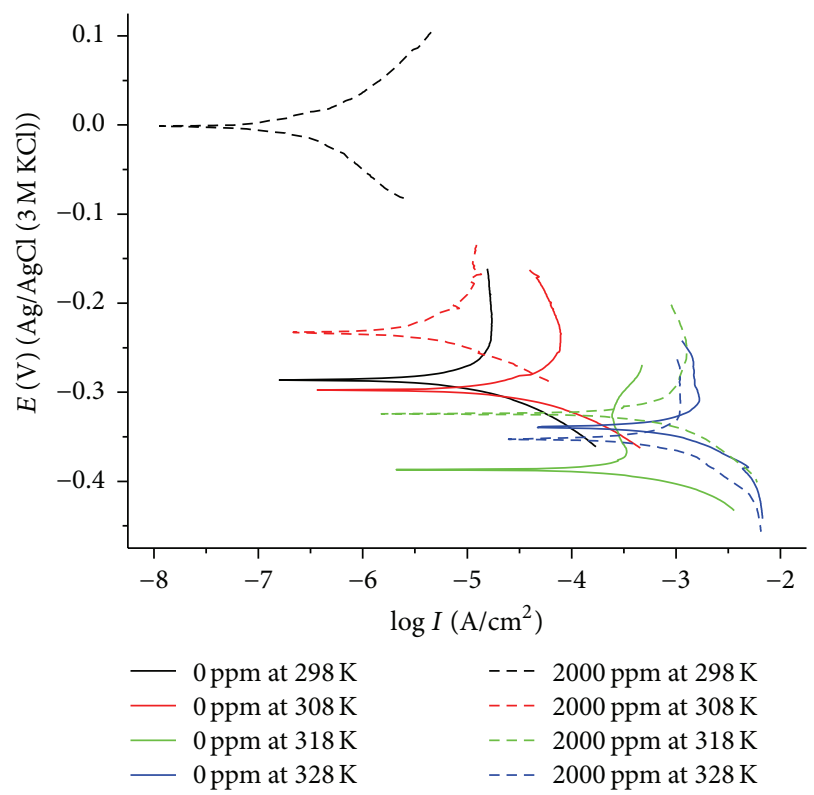

FIgURE 2: Tafel plots of $304 \mathrm{SS}$ in the sulfuric acid $0.5 \mathrm{M}$ without and with inhibitor at temperature variations. 
TABLE 2: The potentiodynamic polarization data of $304 \mathrm{SS}$ in the sulfuric acid $0.5 \mathrm{M}$ without and with inhibitor at temperature variations.

\begin{tabular}{lcccccc}
\hline Concentration of inhibitor $(\mathrm{ppm})$ & Temperature $(\mathrm{K})$ & $\beta_{a}(\mathrm{~V} / \mathrm{dec})$ & $\beta_{c}(\mathrm{~V} / \mathrm{dec})$ & $E_{\text {corr }}(\mathrm{V})$ & $I_{\text {corr }}\left(\mathrm{A} / \mathrm{cm}^{2}\right)$ & $\mathrm{IE}(\%)$ \\
\hline \multirow{4}{*}{0} & 298 & 0.059 & -7.958 & -0.286 & $2.19 \times 10^{-5}$ & - \\
& 308 & 0.057 & -0.739 & -0.297 & $7.12 \times 10^{-5}$ & - \\
& 318 & 0.051 & -0.106 & -0.387 & $1.75 \times 10^{-3}$ & - \\
\hline \multirow{3}{*}{2000} & 328 & 0.148 & 0.342 & -0.339 & $4.04 \times 10^{-3}$ & - \\
& 298 & 0.103 & 0.172 & -0.001 & $5.93 \times 10^{-7}$ & 97.29 \\
& 308 & 0.052 & -0.186 & -0.233 & $1.37 \times 10^{-5}$ & 80.73 \\
& 318 & 0.036 & 0.097 & -0.324 & $0.60 \times 10^{-3}$ & 65.48 \\
& 328 & 0.101 & 1.399 & -0.353 & $2.77 \times 10^{-3}$ & 31.29 \\
\hline
\end{tabular}

TABLE 3: Activation energy value.

\begin{tabular}{lc}
\hline Concentration of inhibitor $(\mathrm{ppm})$ & $E_{a}(\mathrm{~kJ} / \mathrm{mol})$ \\
\hline 0 & 151.21 \\
2000 & 233.93 \\
\hline
\end{tabular}

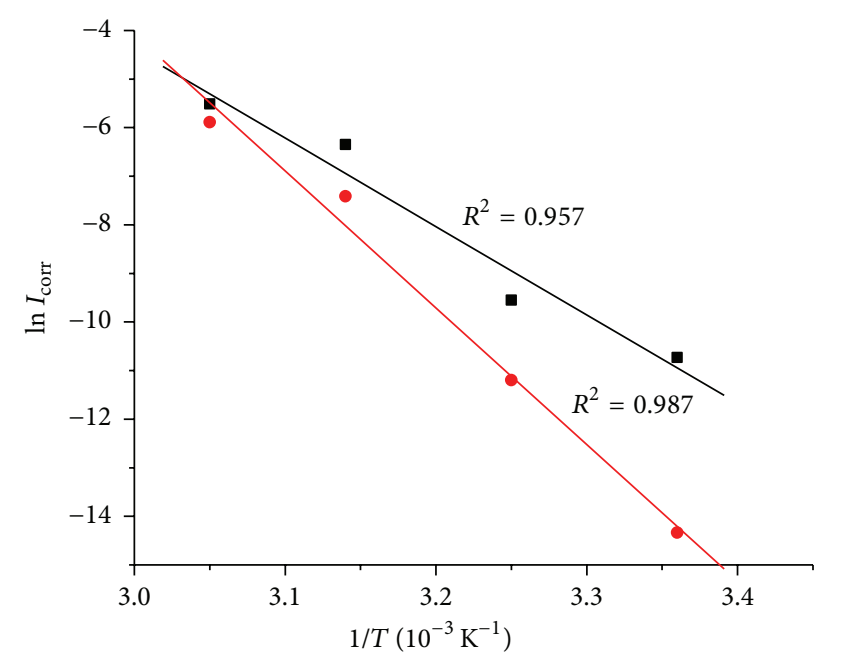

- $0 \mathrm{ppm}$

- $2000 \mathrm{ppm}$

FIGURE 3: Arrhenius plots of 304SS in $0.5 \mathrm{M} \mathrm{H}_{2} \mathrm{SO}_{4}$ without and with inhibitor addition.

Arrhenius equation is

$$
\ln I_{\text {corr }}=\ln A-\frac{E_{a}}{R}\left(\frac{1}{T}\right) .
$$

The effect of temperature towards the corrosion rate can be expressed by Arrhenius equation (3). The Arrhenius equation associated with an activation energy $\left(E_{a}\right)$ which is the minimum energy needed for the reaction to occur. The value of $E_{a}$ can be obtained from the slope of linear regression result between $\ln I_{\text {corr }}$ and $1 / T$ (Figure 3). Calculation of $E_{a}$ value with inhibitor is higher than without inhibitor (Table 3 ). The higher energy activation means that reaction occurs slowly and its corrosion rates are sensitive to temperature [21, 40]. As a consequence, the inhibition process of BWP extract on 304SS surface is difficult to occur at high temperature and tends to cause desorption $[21,41]$. Besides that, the higher $E_{a}$ value with inhibitor also showed BWP extract inhibition on 304 SS corrosion reaction via adsorption $[6,42,43]$. It is associated with increased passive layer formed on the corrosion process [44]. The result of $E_{a}$ value is in good agreement with those obtained from the potentiodynamic polarization and reinforces the physisorption on the 304SS surface by inhibitor molecule. The relationships between IE\%, temperature, and $E_{a}$ value are classified into three groups $[6,45,46]$.

(1) IE\% decreases with increase of temperature: $E_{a}$ (solution with inhibitor) $>E_{a}$ (blank solution).

(2) IE\% increase with increase of temperature: $E_{a}$ (solution with inhibitor) $<E_{a}$ (blank solution).

(3) IE\% does not change with change of temperature: $E_{a}$ (solution with inhibitor) $=E_{a}$ (blank solution).

Based on the result of Tables 2 and 3, the inhibitor in this study (i.e., BWP extract) was included in the first group.

3.3. Adsorption Isotherm of BWP Extract. In general organic molecules can inhibit metal corrosion by means of adsorption [25] that occurs depending on the chemical composition of molecule, temperature, and electrochemical potential on metal or interface solution/metal [22]. Organic compounds are mixed inhibitors that inhibit both the anodic and the cathodic reactions [9, 18, 22]. Information of inhibitor adsorption on metal surface can be shown by adsorption isotherm $[5,7]$. The adsorption isotherm is based on potentiodynamic polarization data. The adsorption isotherm of this study was calculated with some equations: these are Frumkin, Langmuir, Temkin, Freundlich, Bockis-Swinkels, and FloryHuggins [47]. The best fitted result of this study is obeying the Temkin adsorption isotherm equations $(4)[11,48]$ which is shown in Figure 4.

Temkin equation is

$$
\log \frac{\theta}{C}=\log K-g \theta
$$

where $C$ is the concentration of BWP extract, $\theta$ is the degree of surface coverage, $g$ is adsorbate parameter, and $K$ is the adsorption equilibrium constant. Based on (4), the value of $K$ was calculated as 69.183 . 
TABLE 4: Thermodynamic parameters for $304 \mathrm{SS}$ in $0.5 \mathrm{M} \mathrm{H}_{2} \mathrm{SO}_{4}$ without and with inhibitor.

\begin{tabular}{lccc}
\hline $\begin{array}{l}\text { Concentration of } \\
\text { inhibitor }(\mathrm{ppm})\end{array}$ & $\Delta G_{\mathrm{ads}}^{\circ}(\mathrm{kJ} / \mathrm{mol})$ & $\Delta H^{\circ}(\mathrm{kJ} / \mathrm{mol})$ & $\Delta S^{\circ}(\mathrm{J} / \mathrm{mol} \cdot \mathrm{K})$ \\
\hline 0 & - & 150.57 & 169.69 \\
2000 & -20.44 & 234.71 & 424.89 \\
\hline
\end{tabular}

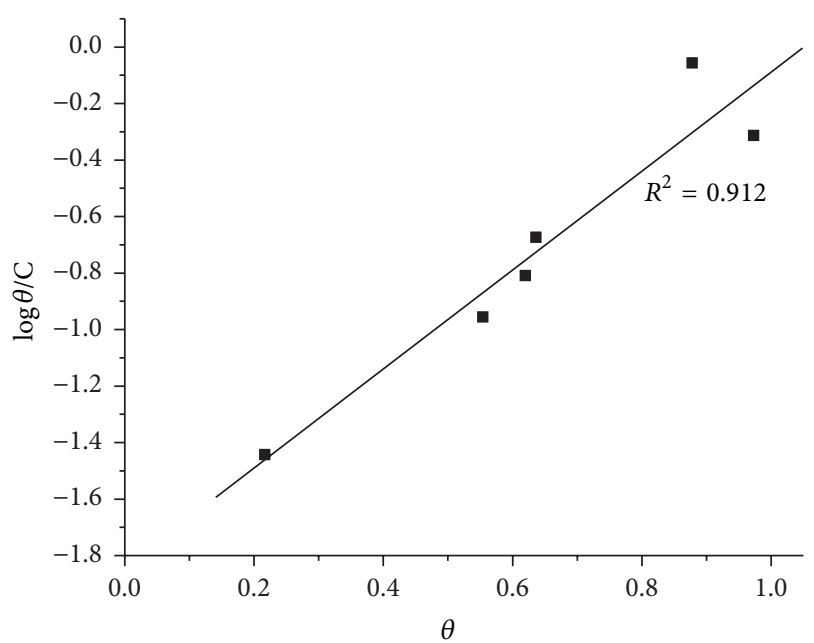

FIGURE 4: Temkin isotherm for the adsorption of BWP extract on 304SS surface.

$K$ is related to the free energy of adsorption by [20]

$$
K=\frac{1}{55.5} \exp \left(\frac{-\Delta G_{\mathrm{ads}}^{\circ}}{R T}\right)
$$

where $\Delta G_{\mathrm{ads}}^{\circ}$ is standard free energy of adsorption. The value of 55.5 is the concentration of water in solution expressed in mol. Generally, values of free energy of adsorption up to $-20 \mathrm{~kJ} / \mathrm{mol}$ are consistent with electrostatic interaction between charged molecules and a charged metal (which indicates physisorption) while those more negative than $-40 \mathrm{~kJ} / \mathrm{mol}$ involve charge sharing or transfer from the inhibitor molecules to the metal surface to form a coordinate type of bond (which indicates chemisorption) [20,45]. The $\Delta G_{\mathrm{ads}}^{\circ}$ value in this study (Table 4 ) is characteristic for physisorption. The negative values for $\Delta G_{\text {ads }}^{\circ}$ ensure the spontaneity of the adsorption of BWP on 304SS surface [7, 20,33]. This result supports the fact that adsorption of BWP extract is physisorption and that it is in a good agreement with the explanation in Section 3.2.

The values of enthalpy of activation $\left(\Delta H^{\circ}\right)$ and entropy of activation $\left(\Delta S^{\circ}\right)$ are calculated from a slope $\left(-\Delta H^{\circ} / R\right)$ and an intercept $\left(\ln (R / N h)+\Delta S^{\circ} / R\right)$ of linear plot in Figure 5 by [37]

$$
I_{\text {corr }}=\left(\frac{R T}{N h}\right) \exp \left(\frac{\Delta S^{\circ}}{R}\right) \exp \left(\frac{-\Delta H^{\circ}}{R}\right),
$$

where $h$ is Planck's constant, $N$ is Avogadro's number, $T$ is the absolute temperature, and $R$ is the universal gas constant. Calculation of the value of $\Delta H^{\circ}$ and $\Delta S^{\circ}$ is summarized in Table 4 . The positive value of $\Delta H^{\circ}$ means the endothermic

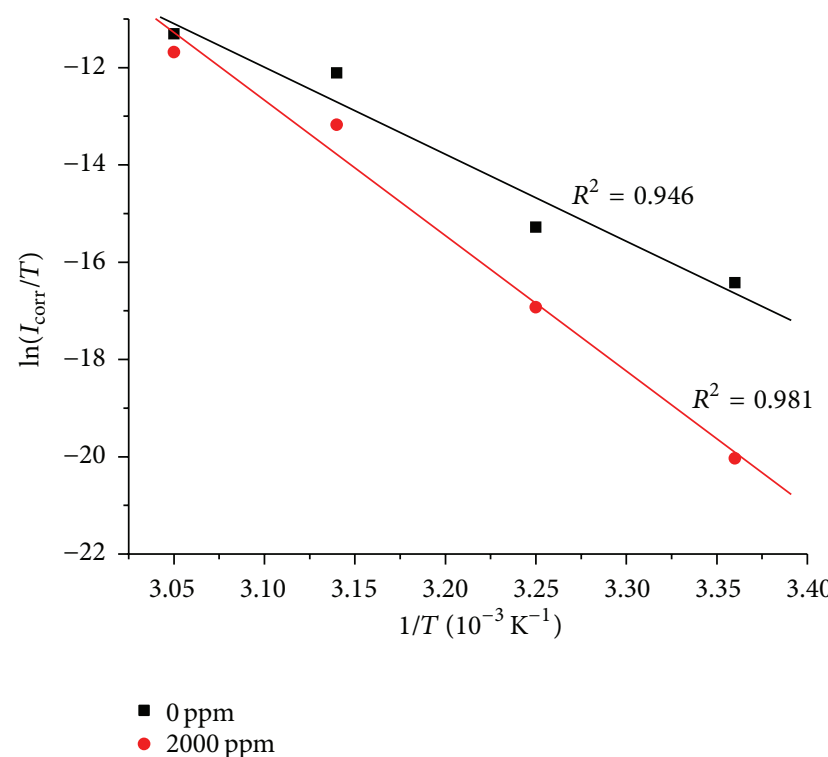

Figure 5: Arrhenius plot for $\ln \left(I_{\text {corr }} / T\right)$ versus $1 / T$ in $0.5 \mathrm{M} \mathrm{H}_{2} \mathrm{SO}_{4}$ without and with inhibitor addition.

nature of metal dissolution process in the presence of the BWP extract [20,37]. The positive value of $\Delta S^{\circ}$ means that the adsorption process is accompanied by an increase in entropy, which is the driving force for the adsorption of inhibitor onto the metal surface [45].

3.4. EIS Measurement. The parameters obtained from the measurement of EIS are the charge transfer resistance $\left(R_{\mathrm{ct}}\right)$, Warburg impedance $(\mathrm{W})$, solution resistance $\left(R_{s}\right)$, and constant phase element (CPE). Figure 6(a) shows the Nyquist plots for 304SS in $0.5 \mathrm{M} \mathrm{H}_{2} \mathrm{SO}_{4}$ solution without and with inhibitor. The interaction between metal surface and solution causes a charge transfer between both of them, measured as $R_{\mathrm{ct}}$ [11]. The semicircle of Nyquist plot (Figure 6(a)) indicated the characteristic of roughness and inhomogeneity electrode surface $[8,49,50]$. Moreover, that semicircle in the high frequency region is attributed to the time constant, which is related to both $R_{\mathrm{ct}}$ and CPE [51]. Warburg impedance was showed by a straight-line in low frequency. $\mathrm{W}$ indicates corrosion reaction within diffusion control that may occur due to the diffusion of reactive species [52]. The equivalent circuit model (Figure 6(a)) illustrates the general case of the frequency response of an interface characterized by charge transfer and diffusion process $[51,53,54]$. In the general frequency, the polarization resistance consists of charge transfer resistance $\left(R_{\mathrm{ct}}\right)$, and another resistance such as diffuse layer resistance, accumulated species at metal/interface solution, and inhibitor film resistance [55]. The CPE indicate a different physical phenomenon such as surface inhomogeneity from surface roughness, inhibitor adsorption, and formation of layer $[56,57]$.

The responses of frequency of these equivalent circuit models (Figure 6(a)) depend on the value of charge transfer resistance $\left(R_{\mathrm{ct}}\right)$ and diffusion resistance $(\mathrm{W})$. That equivalent circuit model used to fit the result of EIS measurement with 
TABLE 5: Fitting results of EIS data for $304 \mathrm{SS}$ in $0.5 \mathrm{M} \mathrm{H}_{2} \mathrm{SO}_{4}$ without and with inhibitor.

\begin{tabular}{lccccccc}
\hline Concentration of inhibitor $(\mathrm{ppm})$ & $R_{s}\left(\Omega \mathrm{cm}^{2}\right)$ & $R_{\mathrm{ct}}\left(\Omega \mathrm{cm}^{2}\right)$ & $\mathrm{CPE}\left(\mu \mathrm{F} / \mathrm{cm}^{2}\right)$ & $n$ & $\begin{array}{c}\mathrm{W} \\
Y_{W}\left(\Omega^{-1} \mathrm{~cm}^{-2} \mathrm{~s}^{0.5}\right)\end{array}$ & $\begin{array}{c}\chi^{2} \\
\mathrm{IE}(\%)\end{array}$ \\
\hline 0 & 8.03 & 24.96 & 377.65 & 0.996 & 0.0691 & 0.0141 & - \\
1000 & 11.35 & 237.50 & 62.11 & 1.003 & 0.0029 & 1.0555 & 89.49 \\
2000 & 11.86 & 290.84 & 59.95 & 1.001 & 0.0020 & 1.1640 & 91.42 \\
3000 & 10.15 & 267.75 & 59.94 & 1.001 & 0.0021 & 0.9351 & 90.68 \\
4000 & 8.59 & 257.96 & 63.35 & 1.001 & 0.0026 & 0.9171 \\
5000 & 8.35 & 242.38 & 68.04 & 1.002 & 0.0031 & 0.8045 \\
6000 & 7.99 & 196.39 & 67.93 & 1.003 & 0.0042 & 0.9013 & 87.29 \\
\hline
\end{tabular}

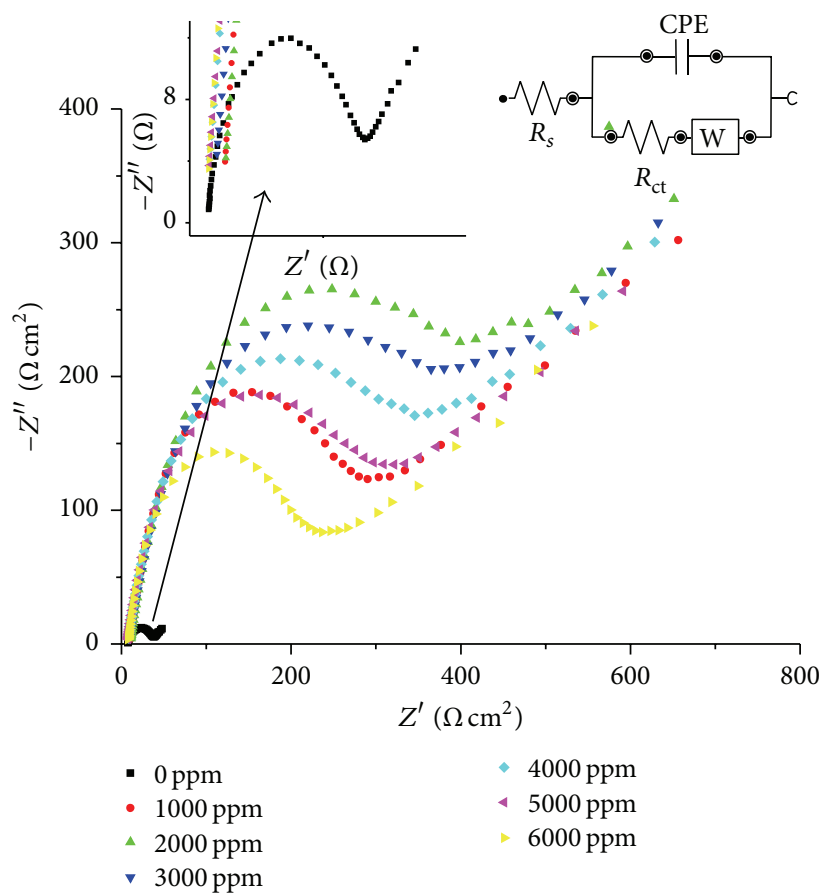

(a)

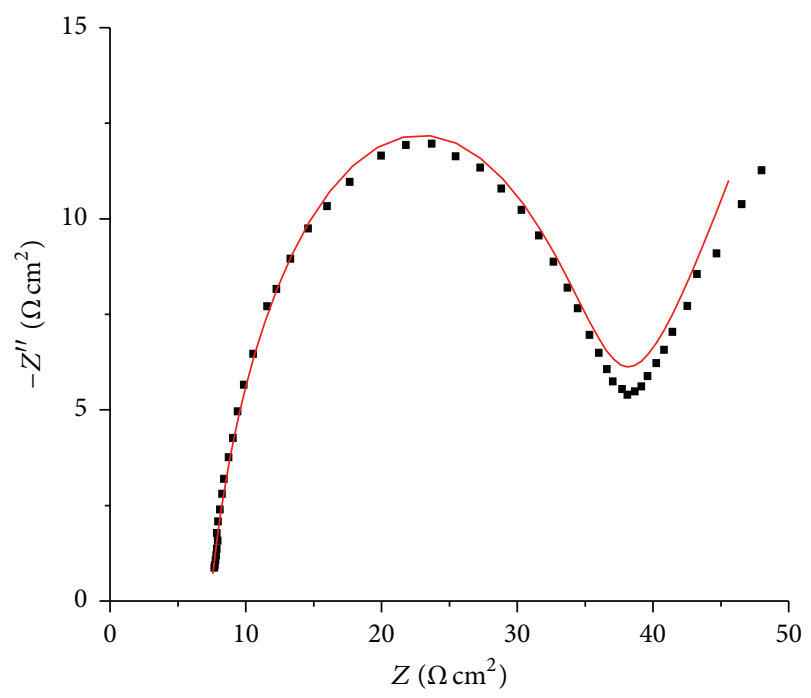

- Experimental
Simulation

(b)

Figure 6: (a) Nyquist plots of 304SS in $0.5 \mathrm{M} \mathrm{H}_{2} \mathrm{SO}_{4}$ with variations of inhibitor concentration and equivalent circuit model used to fit the Nyquist plots, and (b) a representative of fitting example of Nyquist diagrams for $304 \mathrm{SS}$ in $0.5 \mathrm{M} \mathrm{H}_{2} \mathrm{SO}_{4}$ solution.

a representative of fitting example of Nyquist diagrams for $304 \mathrm{SS}$ in $0.5 \mathrm{M} \mathrm{H}_{2} \mathrm{SO}_{4}$ solution is shown in Figure 6(b). Fitting of the experimental result from EIS to equivalent circuit gave all parameters impedance that is summarized in Table 5.

The $R_{\mathrm{ct}}$ value indicates the amount of inhibition from the BWP extract addition $[18,58]$. The diameter of capacitive circle (Figure 6(a)) with inhibitor is larger than that without inhibitor, where the largest diameter was obtained at the inhibitor concentration of $2000 \mathrm{ppm}$. The diameter of capacitive circle which increased at inhibitor $2000 \mathrm{ppm}$ indicated that BWP extract increased the charge transfer resistance and gave an inhibition effect on the 304SS corrosion in $0.5 \mathrm{M} \mathrm{H}_{2} \mathrm{SO}_{4}$ [51]. Increasing of the $R_{\mathrm{ct}}$ value with inhibitor addition of $2000 \mathrm{ppm}$ gave a better performance to retard corrosion because of the oxide layer formation $[8,11,53]$.
The inhibition efficiency (IE\%) from this method reached 91.42\% (Table 5), which is in a good agreement with the potentiodynamic polarization method.

3.5. Mechanism of Corrosion Inhibition. Inhibitor can retard the corrosion rate of metal in various ways; one of them is via adsorption process. Adsorption retards the corrosion rate by increasing or decreasing the reactant diffusion rate to surface metal and by reducing the electric resistance from the metal surface $[13,19]$. Based on the potentiodynamic polarization measurement, the IE\% decrease with increasing temperature indicates that physisorption occurred on 304SS surface by inhibitor molecule. The increasing of $R_{\mathrm{ct}}$ value and decreasing of CPE value also showed adsorption process. The quercetin (Figure $7(\mathrm{a})$ ) as main compound of the BWP extract has active sites in form of $p$ electron of $\mathrm{O}$ atom and $\pi$ bond of 
<smiles>O=c1c(O)c(-c2ccc(O)c(O)c2)oc2cc(O)cc(O)c12</smiles>

(a)

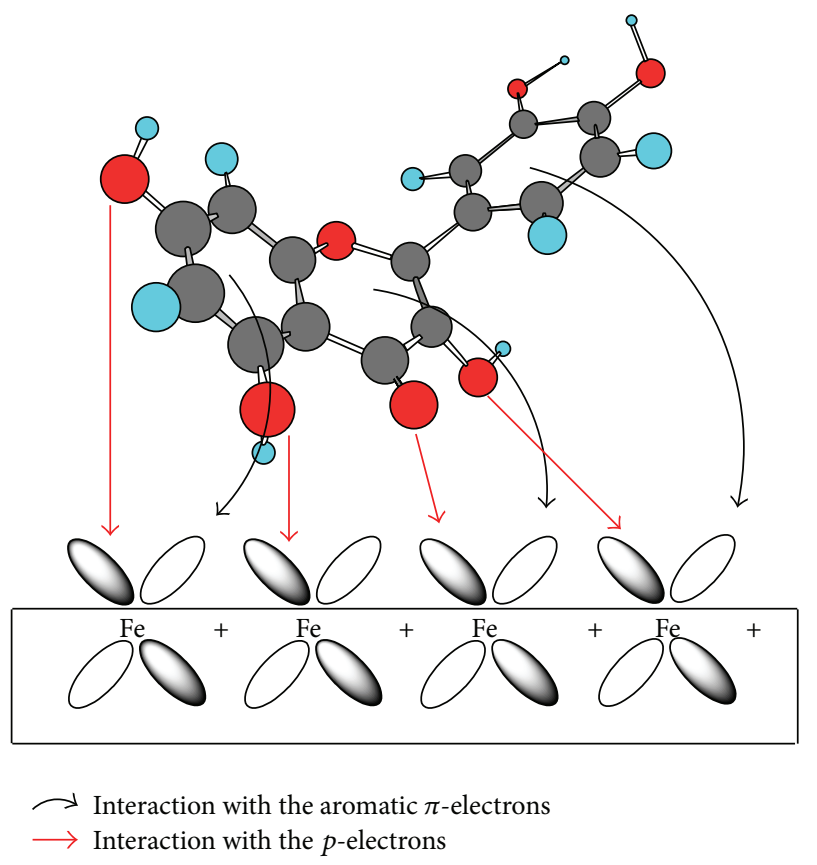

(b)

FIGURE 7: (a) Chemical structure of quercetin and (b) interaction of quercetin active sites with the 304SS surface [30].

aromatic rings [30] that can interact with the vacant $d$ orbital of Fe as shown in Figure 7(b). Those interactions will form thin protective layer (Fe-quercetin complex) which protect the 304SS from the aggressiveness of sulfuric acid.

The result of $X$-ray diffraction (XRD) on Figure 8 shows the presence of $\mathrm{Fe}_{2} \mathrm{O}_{3}$ and $\mathrm{Cr}_{2} \mathrm{O}_{3}$, in testing solution either without or with inhibitor addition. There was a smooth surface on metal surface to prevent the corrosion of 304SS through adsorption of the inhibitors on metal surface [23, 59]. At solution without inhibitor, actually the 304SS has passive layer (in the form of $\mathrm{Cr}_{2} \mathrm{O}_{3}$ which contains $\mathrm{Ni}$ ) that directly contacts with the solution and caused concentration of $\mathrm{Cr}^{3+}$ and $\mathrm{Ni}^{2+}$ ions to increase. At this condition, $\mathrm{Fe}$ is still being protected by that passive layer. Longer contact with the solution may cause the $\mathrm{Cr}^{3+}$ ion to decompose completely and $\mathrm{Fe}$ will be oxidized [60]. The testing solution with inhibitor shows that the presence of $\mathrm{Fe}_{2} \mathrm{O}_{3}$ and $\mathrm{Cr}_{2} \mathrm{O}_{3}$ peaked at angle of $2 \theta=44.482$ and 75.374 that was related to $\left(\begin{array}{lll}-4 & 0 & 0\end{array}\right)$ and $\left(\begin{array}{lll}6 & 2 & 2\end{array}\right)$ planes, respectively. The intensity of $\mathrm{Cr}_{2} \mathrm{O}_{3}$ peak in solution with inhibitor is lower than that without inhibitor. This shows that $\mathrm{Cr}_{2} \mathrm{O}_{3}$ has dissolved more and cannot protect the 304SS from the aggressiveness of sulfuric acid; therefore, the bigger $\mathrm{Fe}_{2} \mathrm{O}_{3}$ (53.34\%) was formed. That $\mathrm{Cr}_{2} \mathrm{O}_{3}$ passive layer is changed by a thin protective layer as the result of inhibitor molecule adsorption on the 304SS surface. That thin protective layer is shown by the presence of $\mathrm{Fe}-\mathrm{CHO}$ peak at angle $2 \theta=42.267$ that was related to ( $\left.\begin{array}{lll}1 & 1 & 1\end{array}\right)$ plane. At the interface of metal/acid solution, the dissolution of iron will produce $\mathrm{Fe}^{2+}$ ion such as explained by

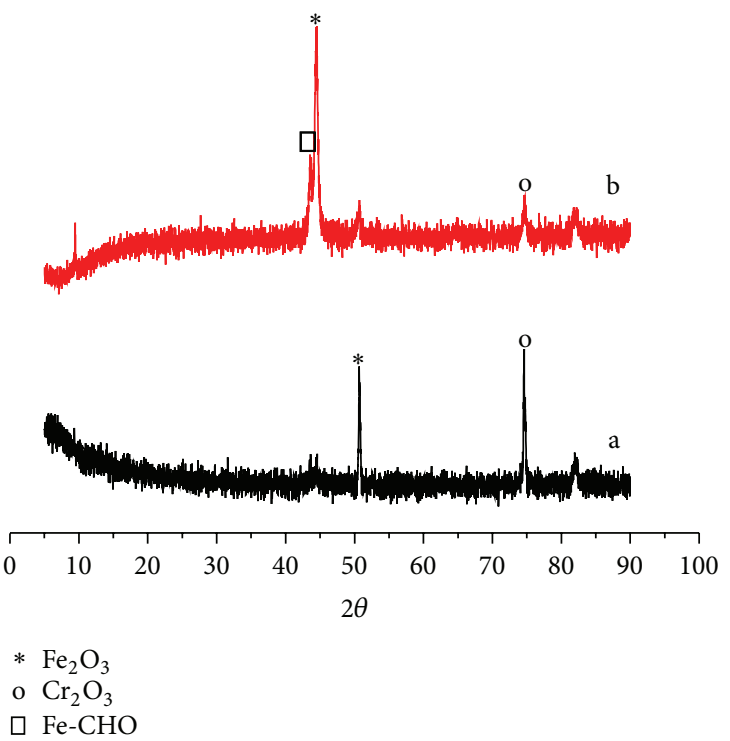

FIGURE 8: X-ray diffraction patterns of $304 \mathrm{SS}$ in $0.5 \mathrm{M} \mathrm{H}_{2} \mathrm{SO}_{4}$ without (a) and with (b) inhibitor at temperature $298 \mathrm{~K}$.

Garai et al. (2012) [59]. Inhibitor molecules adsorb on the 304SS surface and replace water molecules by transforming to higher stable iron-inhibitor complex [59]. The formation of this complex has also been confirmed by EIS. 
TABLE 6: Properties of honey derivatives as corrosion inhibitor.

\begin{tabular}{|c|c|c|c|c|}
\hline Media & Substrate & Method & Max. IE (\%) & Ref. \\
\hline $0.5 \mathrm{NaCl}$ & Copper & Weight loss, potentiostatic polarization & 89.00 & {$[11]$} \\
\hline Aqueous and $3 \% \mathrm{NaCl}$ & Tin & Potentiostatic polarization & 90.00 & {$[16]$} \\
\hline High saline water & Carbon steel & Weight loss, potentiostatic polarization & 91.23 & {$[24]$} \\
\hline $3.5 \% \mathrm{NaCl}$ & Aluminium alloy & Potentiodynamic polarization, EIS measurement, and DEIS measurement & 73.00 & {$[25]$} \\
\hline $0.5 \mathrm{NaCl}$ & CuNiFe alloy & Potentiodynamic polarization, EIS measurement & 70.06 & [34] \\
\hline
\end{tabular}

The results of investigation have shown that BWP extract act as good corrosion inhibitor for $304 \mathrm{SS}$ in $0.5 \mathrm{M}$ sulfuric acid. Similar results were obtained using honey derivative as inhibitor in corrosion investigation on carbon steel [15], copper [24], aluminium [25], and CuNiFe [34] alloy in salt environment. Moreover, other investigations reported that the synergistic effect between honey and black radish juice increased the inhibition efficiency on corrosion of tin in aqueous and sodium chloride [16]. The observation that we conducted in the present study was in sulfuric acid solution which makes it different to investigations. There were differences of inhibition efficiency due to the chemical composition of honey derivatives. The comparisons of the investigations result were listed in Table 6 .

\section{Conclusions}

(1) The extract of bee wax propolis (BWP) acts as good inhibitor for corrosion process of $304 \mathrm{SS}$ in $0.5 \mathrm{M}$ sulfuric acid solution.

(2) The optimum inhibition efficiency is $97.29 \%$ and $91.42 \%$ at 2000 ppm using potentiodynamic polarization and EIS measurement, respectively.

(3) The effect of temperature revealed physisorption for the inhibition properties of the BWP extract and it obeyed Temkin adsorption isotherm.

(4) Calculation of the $\Delta G_{\text {ads }}^{\circ}$ value $(-20.44 \mathrm{~kJ} / \mathrm{mol})$ also supports the case of physisorption by BWP extract on the 304 SS surface.

(5) A thin protective layer formed was confirmed by XRD analysis where there is the presence of Fe-CHO peak in the solution with inhibitor addition.

\section{Conflict of Interests}

The authors declare that there is no conflict of interests regarding the publication of this paper.

\section{Acknowledgments}

The authors are grateful to Dr. rer. nat. Fredy Kurniawan as the Head of Laboratory of Instrumentation and Analytical Sciences, Institut Teknologi Sepuluh Nopember, Surabaya, Indonesia, for the use of laboratory facilities. The authors also thank Kartika A. Madurani for all her support and technical assistance.

\section{References}

[1] A. S. Fouda and A. S. Ellithhy, "Inhibition effect of 4-phenyltiazole derivatives on corrosion of 304L stainless steel in $\mathrm{HCl}$ solution," Corrosion Science, vol. 52, pp. 868-875, 2009.

[2] C. H. Musinoi Hagen, The Influence of Alternating Current on the Polarization Behavior of Stainless Steel, Department of Materials Science and Engineering, NTNU-Trondheim Norwegian University of Science and Technology, 2013.

[3] U. C. Nwaogu, C. Blawert, N. Scharnagl, W. Dietzel, and K. U. Kainer, "Influence of inorganic acid pickling on the corrosion resistance of magnesium alloy AZ31 sheet," Corrosion Science, vol. 51, no. 11, pp. 2544-2556, 2009.

[4] D. Talbot, Corrosion Science and Technology, CRC Press, Boca Raton, Fla, USA, 1st edition, 1998.

[5] L. Bammou, M. Belkhaouda, R. Salghi et al., "Corrosion inhibition of steel in sulfuric acidic solution by the Chenopodium Ambrosioides extracts," Journal of the Association of Arab Universities for Basic and Applied Sciences, vol. 16, pp. 83-90, 2014.

[6] N. O. Obi-Egbedi, I. B. Obot, and S. A. Umoren, "Spondias mombin L. as a green corrosion inhibitor for aluminium in sulphuric acid: correlation between inhibitive effect and electronic properties of extracts major constituents using density functional theory," Arabian Journal of Chemistry, vol. 5, no. 3, pp. 361-373, 2012.

[7] M. Hazwan Hussin, M. Jain Kassim, N. N. Razali, N. H. Dahon, and D. Nasshorudin, "The effect of Tinospora crispa extracts as a natural mild steel corrosion inhibitor in $1 \mathrm{M} \mathrm{HCl}$ solution," Arabian Journal of Chemistry, 2011.

[8] R. S. Gonçalves, D. S. Azambuja, and A. M. Serpa Lucho, "Electrochemical studies of propargyl alcohol as corrosion inhibitor for nickel, copper, and copper/nickel (55/45) alloy," Corrosion Science, vol. 44, no. 3, pp. 467-479, 2002.

[9] E. Stupnišek-Lisac, A. Gazivoda, and M. Madžarac, "Evaluation of non-toxic corrosion inhibitors for copper in sulphuric acid," Electrochimica Acta, vol. 47, no. 26, pp. 4189-4194, 2002.

[10] S. A. Abd El-Maksoud, "Some phthalazin derivatives as non toxic corrosion inhibitors for copper in sulphuric acid," Electrochimica Acta, vol. 49, no. 24, pp. 4205-4212, 2004.

[11] M. H. Hussin and M. J. Kassim, "Electrochemical, thermodynamic and adsorption studies of (+-) catechin hydrate as natural mild steel corrosion inhibitor in $1 \mathrm{M} \mathrm{HCl,"} \mathrm{International} \mathrm{Journal}$ of Electrochemical Science, vol. 6, no. 5, pp. 1396-1414, 2011.

[12] V. S. Sastri, Green Corrosion Inhibitors Theory and Practice, Wiley, Yukon, Canada, 2011.

[13] P. B. Raja and M. G. Sethuraman, "Natural products as corrosion inhibitor for metals in corrosive media-a review," Materials Letters, vol. 62, no. 1, pp. 113-116, 2008. 
[14] L. Wang, "Inhibition of mild steel corrosion in phosphoric acid solution by triazole derivatives," Corrosion Science, vol. 48, no. 3, pp. 608-616, 2006.

[15] A. Y. El-Etre, "Natural honey as corrosion inhibitor for metals and alloys. I. Copper in neutral aqueous solution," Corrosion Science, vol. 40, no. 11, pp. 1845-1850, 1998.

[16] I. Radojčić, K. Berković, S. Kovač, and J. Vorkapić-Furač, "Natural honey and black radish juice as tin corrosion inhibitors," Corrosion Science, vol. 50, no. 5, pp. 1498-1504, 2008.

[17] Y. Abboud, A. Abourriche, T. Saffaj et al., "A novel azo dye, 8quinolinol-5-azoantipyrine as corrosion inhibitor for mild steel in acidic media," Desalination, vol. 237, no. 1-3, pp. 175-189, 2009.

[18] A. Ostovari, S. M. Hoseinieh, M. Peikari, S. R. Shadizadeh, and S. J. Hashemi, "Corrosion inhibition of mild steel in $1 \mathrm{M} \mathrm{HCl}$ solution by henna extract: a comparative study of the inhibition by henna and its constituents (lawsone, gallic acid, $\alpha$-d-glucose and tannic acid)," Corrosion Science, vol. 51, no. 9, pp. 1935-1949, 2009.

[19] F. Zucchi and I. H. Omar, "Plant extracts as corrosion inhibitors of mild steel in $\mathrm{HCl}$ solutions," Surface Technology, vol. 24, no. 4, pp. 391-399, 1985.

[20] S. A. Umoren, I. B. Obot, E. E. Ebenso, and N. O. Obi-Egbedi, "The Inhibition of aluminium corrosion in hydrochloric acid solution by exudate gum from Raphia hookeri," Desalination, vol. 247, no. 1-3, pp. 561-572, 2009.

[21] A. Y. El-Etre, "Inhibition of aluminum corrosion using Opuntia extract," Corrosion Science, vol. 45, no. 11, pp. 2485-2495, 2003.

[22] E. E. Oguzie, "Corrosion inhibition of aluminium in acidic and alkaline media by Sansevieria trifasciata extract," Corrosion Science, vol. 49, no. 3, pp. 1527-1539, 2007.

[23] P. B. Raja and M. G. Sethuraman, "Inhibitive effect of black pepper extract on the sulphuric acid corrosion of mild steel," Materials Letters, vol. 62, no. 17-18, pp. 2977-2979, 2008.

[24] A. Y. El-Etre and M. Abdallah, "Natural honey as corrosion inhibitor for metals and alloys. II. C-steel in high saline water," Corrosion Science, vol. 42, no. 4, pp. 731-738, 2000.

[25] H. Gerengi, H. Goksu, and P. Slepski, “The inhibition effect of mad honey on corrosion of 2007-type aluminium alloy in 3.5\% Nacl Solution," Materials Research, vol. 17, no. 1, pp. 255-264, 2014.

[26] X. L. Cheng, H. Y. Ma, S. H. Chen, R. Yu, X. Chen, and Z. M. Yao, "Corrosion of stainless steels in acid solutions with organic sulfur-containing compounds," Corrosion Science, vol. 41, no. 2, pp. 321-333, 1998.

[27] R. Agrawal and T. K. G. Namboodhiri, "The inhibition of corrosion and hydrogen embrittlement of AISI 410 stainless steel," Journal of Applied Electrochemistry, vol. 22, no. 4, pp. 383-389, 1992.

[28] M. Abdallah, "Rhodanine azosulpha drugs as corrosion inhibitors for corrosion of 304 stainless steel in hydrochloric acid solution," Corrosion Science, vol. 44, no. 4, pp. 717-728, 2002.

[29] E. E. Oguzie, "Evaluation of the inhibitive effect of some plant extracts on the acid corrosion of mild steel," Corrosion Science, vol. 50, no. 11, pp. 2993-2998, 2008.

[30] G. Chen, M. Zhang, J. Zhao, R. Zhou, Z. Meng, and J. Zhang, "Investigation of Ginkgo biloba leave extracts as corrosion and oil field microorganism inhibitors," Chemistry Central Journal, vol. 7, article 83, 2013.

[31] ASTM, "Practice for preparing, cleaning and evaluating corrosion test specimens," ASTM G1-72, ASTM International, West Conshohocken, Pa, USA, 1990.
[32] E. Stupnišek-Lisac, A. L. Božić, and I. Cafuk, "Low-toxicity copper corrosion inhibitors," Corrosion, vol. 54, no. 9, pp. 713-720, 1998.

[33] M. I. Awad, "Eco friendly corrosion inhibitors: inhibitive action of quinine for corrosion of low carbon steel in $1 \mathrm{M} \mathrm{HCl}$," Journal of Applied Electrochemistry, vol. 36, no. 10, pp. 1163-1168, 2006.

[34] L. Vrsalović, S. Gudić, and M. Kliškić, “Salvia officinalis L. honey as corrosion inhibitor for CuNiFe in sodium chloride solution," Indian Journal of Chemical Technology, vol. 19, pp. 96-102, 2012.

[35] F. Kandemirli and S. Sagdinc, "Theoretical study of corrosion inhibition of amides and thiosemicarbazones," Corrosion Science, vol. 49, no. 5, pp. 2118-2130, 2007.

[36] A. M. Fekry and M. A. Ameer, "Electrochemical investigation on the corrosion and hydrogen evolution rate of mild steel in sulphuric acid solution," International Journal of Hydrogen Energy, vol. 36, no. 17, pp. 11207-11215, 2011.

[37] M. A. Quraishi, A. Singh, V. K. Singh, D. K. Yadav, and A. K. Singh, "Green approach to corrosion inhibition of mild steel in hydrochloric acid and sulphuric acid solutions by the extract of Murraya koenigii leaves," Materials Chemistry and Physics, vol. 122, no. 1, pp. 114-122, 2010.

[38] E. E. Oguzie, C. Unaegbu, C. N. Ogukwe, B. N. Okolue, and A. I. Onuchukwu, "Inhibition of mild steel corrosion in sulphuric acid using indigo dye and synergistic halide additives," Materials Chemistry and Physics, vol. 84, no. 2-3, pp. 363-368, 2004.

[39] E. E. Ebenso, N. O. Eddy, and A. O. Odiongenyi, "Corrosion inhibition and adsorption properties of Methocarbamol and mild steel in acidic medium," Portugaliae Electrochimica Acta, vol. 27, no. 1, pp. 13-22, 2009.

[40] A. K. Satapathy, G. Gunasekaran, S. C. Sahoo, K. Amit, and P. V. Rodrigues, "Corrosion inhibition by Justicia gendarussa plant extract in hydrochloric acid solution," Corrosion Science, vol. 51, no. 12, pp. 2848-2856, 2009.

[41] A. S. Fouda, G. Y. Elewady, and M. N. El-Haddad, "Corrosion inhibition of carbon steel in acidic solution using some azodyes," Canadian Journal on Scientific and Industrial Research, vol. 2, no. 1, pp. 1-18, 2011.

[42] E. E. Ebenso, "Synergistic effect of halide ions on the corrosion inhibition of Aluminium in $\mathrm{H}_{2} \mathrm{SO}_{4}$ using 2-acetylphenothiazine," Materials Chemistry and Physics, vol. 79, no. 1, pp. 58-70, 2003.

[43] S. A. Umoren and I. B. Obot, "Polyvinylpyrollidone and polyacrylamide as corrosion inhibitors for mild steel in acidic medium," Surface Review and Letters, vol. 15, no. 3, pp. 277-286, 2008.

[44] L. Larabi, O. Benali, and Y. Harek, "Corrosion inhibition of cold rolled steel in $1 \mathrm{M} \mathrm{HClO}_{4}$ solutions by $N$-naphtyl $N^{\prime}$ phenylthiourea," Materials Letters, vol. 61, no. 14-15, pp. 32873291, 2007.

[45] X. Li, S. Deng, H. Fu, and T. Li, "Adsorption and inhibition effect of 6-benzylaminopurine on cold rolled steel in 1.0 M HCl," Electrochimica Acta, vol. 54, no. 16, pp. 4089-4098, 2009.

[46] A. R. S. Priya, V. S. Muralidharam, and A. Subramania, "Development of novel acidizing inhibitors for carbon steel corrosion in $15 \%$ boiling hydrochloric acid," Corrosion Science, vol. 64, pp. 541-552, 2008.

[47] A. K. Maayta and N. A. F. Al-Rawashdeh, "Inhibition of acidic corrosion of pure aluminum by some organic compounds," Corrosion Science, vol. 46, no. 5, pp. 1129-1140, 2004. 
[48] M. H. Hussin and M. J. Kassim, "The corrosion inhibition and adsorption behavior of Uncaria gambir extract on mild steel in 1 M HCl," Materials Chemistry and Physics, vol. 125, no. 3, pp. 461-468, 2011.

[49] K. Jüttner, "Electrochemical impedance spectroscopy (EIS) of corrosion processes on inhomogeneous surfaces," Electrochimica Acta, vol. 35, no. 10, pp. 1501-1508, 1990.

[50] T. Pajkossy, "Impedance of rough capacitive electrodes," Journal of Electroanalytical Chemistry, vol. 364, no. 1-2, pp. 111-125, 1994.

[51] B. Qian, B. Hou, and M. Zheng, "The inhibition effect of tannic acid on mild steel corrosion in seawater wet/dry cyclic conditions," Corrosion Science, vol. 72, pp. 1-9, 2013.

[52] H. Y. Ma, S. H. Chen, B. S. Yin, S. Y. Zhao, and X. Q. Liu, "Impedance spectroscopic study of corrosion inhibition of copper by surfactants in the acidic solutions," Corrosion Science, vol. 45, no. 5, pp. 867-882, 2003.

[53] B. Scrosati, Impedanza Elettrochimica, Corso Teorico-Pratico, SCI, Modena, Italy, 1987.

[54] G. Quartarone, M. Battilana, L. Bonaldo, and T. Tortato, "Investigation of the inhibition effect of indole-3-carboxylic acid on the copper corrosion in $0.5 \mathrm{M} \mathrm{H}_{2} \mathrm{SO}_{4}$," Corrosion Science, vol. 50, no. 12, pp. 3467-3474, 2008.

[55] A. Döner, R. Solmaz, M. Özcan, and G. Kardaş, "Experimental and theoretical studies of thiazoles as corrosion inhibitors for mild steel in sulphuric acid solution," Corrosion Science, vol. 53, no. 9, pp. 2902-2913, 2011.

[56] C. H. Hsu and F. Mansfeld, "Concernng the conversion of the constant phase element parameter $\mathrm{Y}_{0}$ into a capacitance," Corrosion, vol. 57, no. 9, pp. 747-748, 2001.

[57] P. Bommersbach, C. Alemany-Dumont, J.-P. Millet, and B. Normand, "Hydrodynamic effect on the behaviour of a corrosion inhibitor film: characterization by electrochemical impedance spectroscopy," Electrochimica Acta, vol. 51, no. 19, pp. 4011-4018, 2006.

[58] M. Abdallah, B. A. AL Jahdaly, and O. A. Al-Malyo, "Corrosion inhibition of carbon steel in hydrochloric acid solution using non-ionic surfactants derived from phenol compounds," International Journal Electrochemistry Science, vol. 10, pp. 2740-2754, 2015.

[59] S. Garai, S. Garai, P. Jaisankar, J. K. Singh, and A. Elango, “A comprehensive study on crude methanolic extract of Artemisia pallens (Asteraceae) and its active component as effective corrosion inhibitors of mild steel in acid solution," Corrosion Science, vol. 60, pp. 193-204, 2012.

[60] M. Abdallah, "Corrosion behaviour of 304 stainless steel in sulphuric acid solutions and its inhibition by some substituted pyrazolones," Materials Chemistry and Physics, vol. 82, no. 3, pp. 786-792, 2003. 

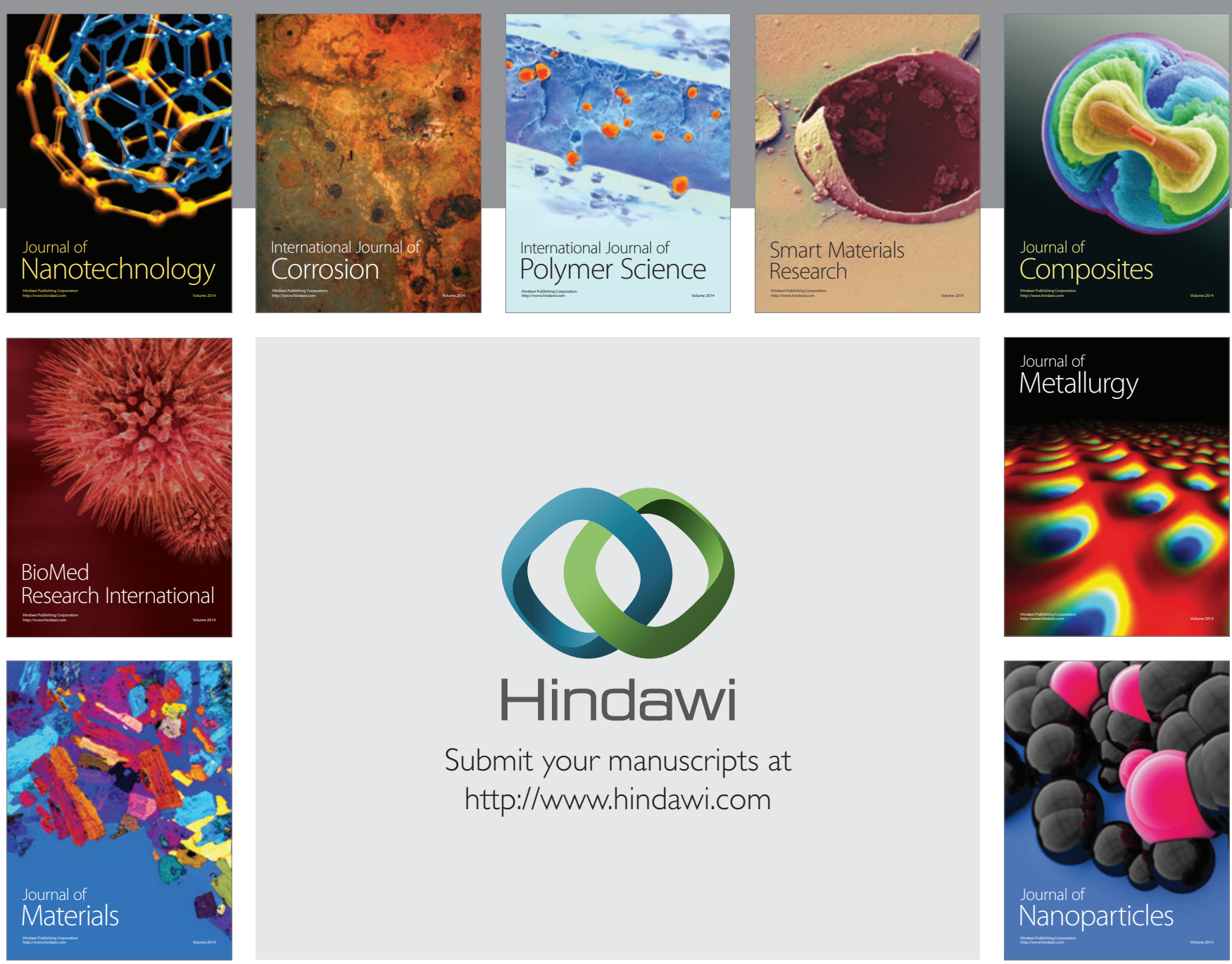

Submit your manuscripts at http://www.hindawi.com
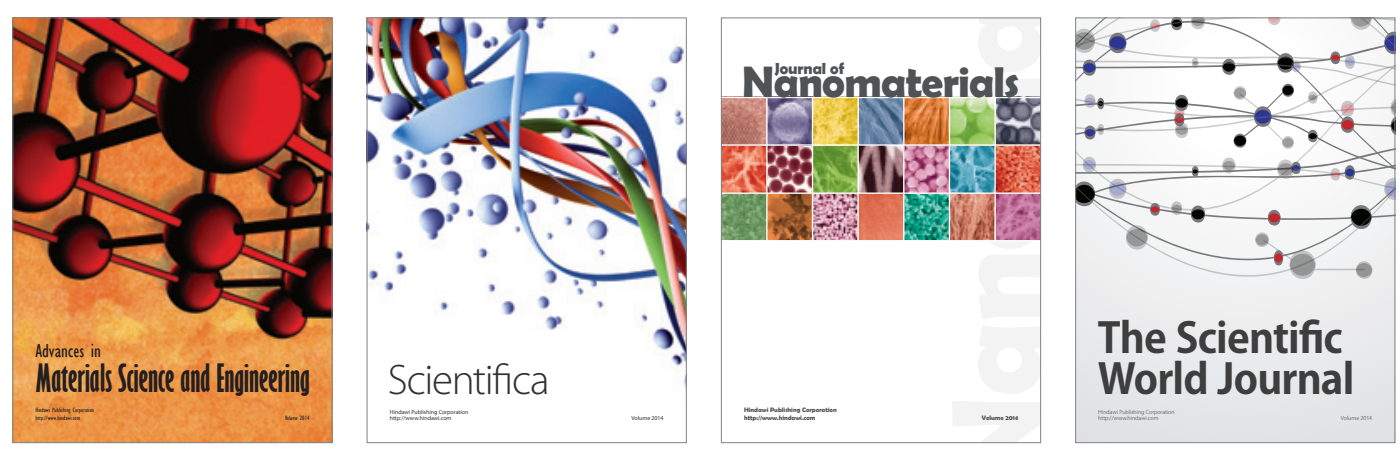

\section{The Scientific World Journal}
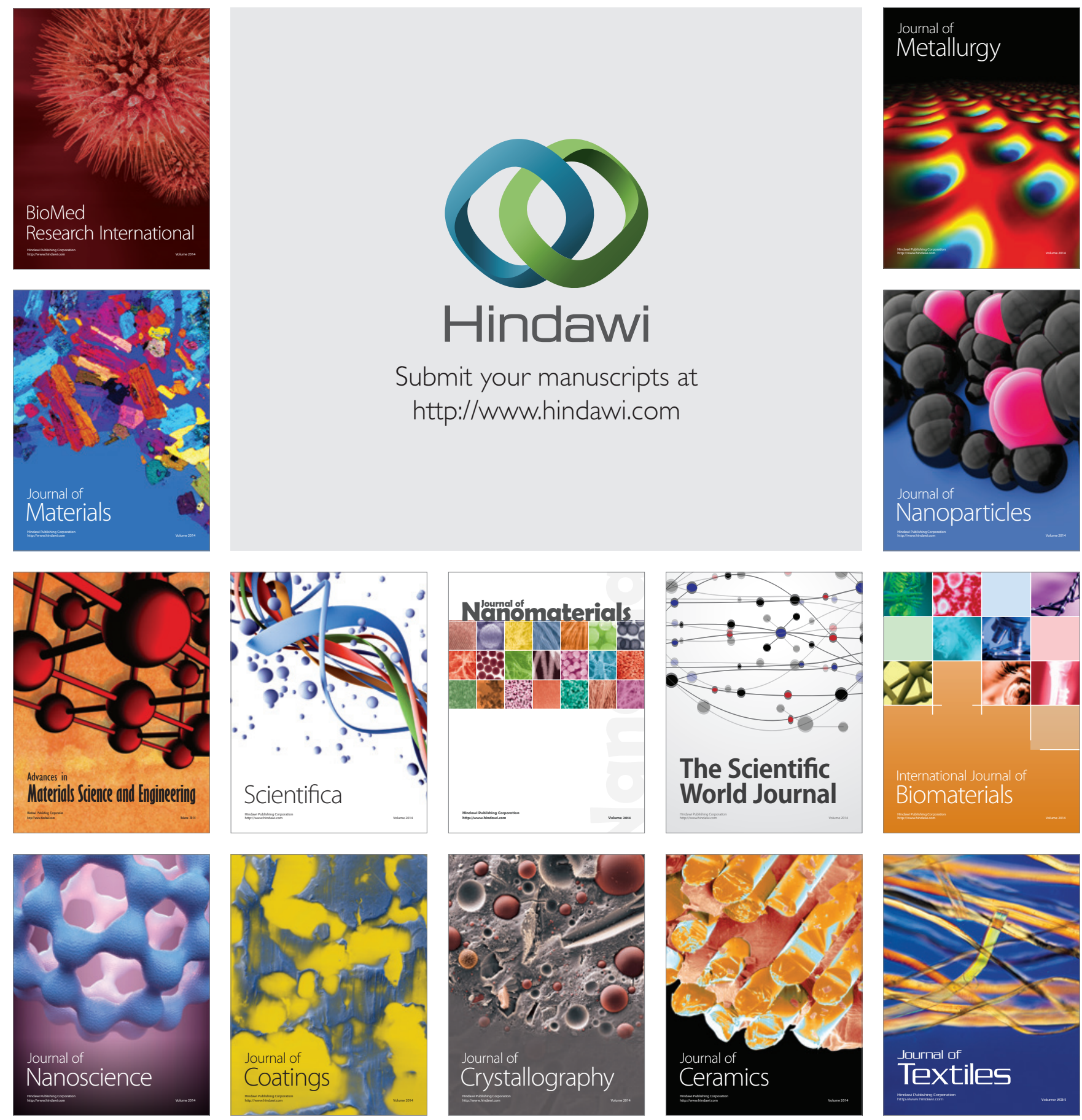